\title{
Advancing psychological assessment in Africa: Contributions from the African Journal of Psychological Assessment
}

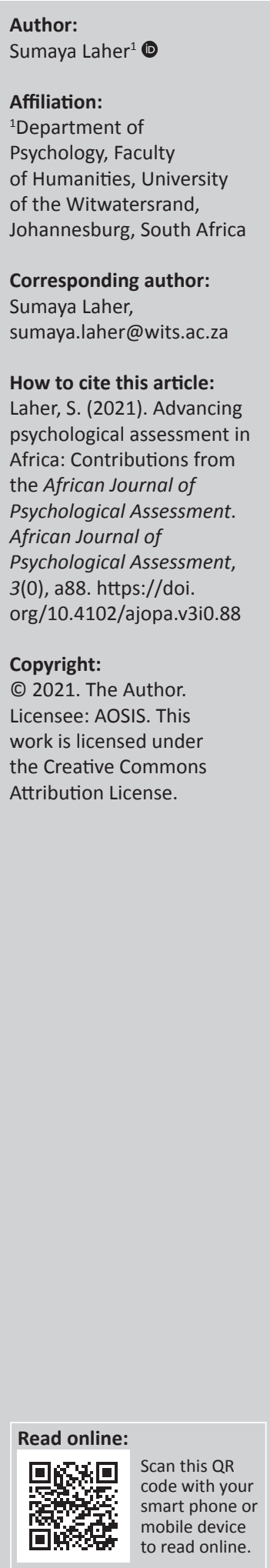

The last 2 years have been challenging across all spheres of our lives. From March 2020 to date, things we all knew and took for granted - from work to school, to relationships and social interactions - have fundamentally changed. The coronavirus disease 2019 (COVID-19) pandemic and subsequent restrictions placed on individual movements and interactions have necessitated a rethinking in all fields in psychology including psychological assessment. In this volume a special section guest edited by August and Mashegoane (2021), provides some insight into the effects of the pandemic on the field of psychological assessment. This ranges from practical and logistical issues such as how to make assessment remotely or face to face whilst complying with preventative measures, as well as ethical issues linked to conducting tests in the online space. Dowdeswell and Kriek (2021) discuss recent trends in unproctored internet testing (UIT) and virtual or video interviewing technologies, and reflect on the role of assessment practices in retrenchment and restructuring in corporates. The advent of COVID-19 had a huge impact on higher education, particularly on professional training programmes which involve substantial practical and hands-on training. Munnik, Smith, Adams Tucker and Human (2021) present a case study from the Masters in Clinical Psychology programme at the University of Western Cape discussing the challenges faced in teaching psychological assessment and the methods adopted in adjusting during this time. Wigdorowitz, Rajab, Hassem and Titi (2021) discuss the impact of COVID-19 across both industry and academia, providing suggestions for conducting assessments remotely and issues to consider. Makhubela and Mashegoane (2021) discuss the psychometric properties of the Fear of COVID-19 scale (FCV-19S) in a South African context. Whilst it is clear across the articles that switching to virtual modes of assessing has its drawbacks, August and Mashegoane (2021) note importantly in their editorial the positive contributions to the field in terms of ensuring greater access to assessment.

Despite the pandemic, the African Journal of Psychological Assessment (AJOPA) has continued to grow as evidenced by the increasing number, and varied nature, of submissions. The inaugural volume included a modest offering of six research articles representing the diverse and creative work from cognitive and personality assessment through to emotional screening. Volume 2 expanded to include seven research articles, two review articles, and a book review with content spanning organisational, neuropsychological, vocational and educational assessments. Cockcroft's (2020) editorial highlighted the misuses of assessment in South Africa arguing that it is imperative for 'practitioners and researchers in Africa, not to allow such problematic research and to make a positive contribution to the body of knowledge through sound and ethical practices' (p. 2). This year the journal has expanded further to include 10 research articles which reflect current research in South Africa.

In this volume, the assessment work that traverses the organisational, clinical and developmental fields has been published. Munnik, Wagener and Smith (2021) consider the screening of emotional and social readiness for school, whilst Abdool Gafoor, Burke and Fourie (2021) investigate the efficacy of the Senior South African Individual Scale-Revised (SSAIS-R) in children with Attentiondeficit/hyperactivity disorder (ADHD). Both these articles touch on the need to consider the lived realities of children in South Africa when assessing. Psychological wellbeing is a core concern more so because this has been identified by the World Health Organization (WHO) as a Sustainable Development Goal (SDG). This is even more crucial given the actual and predicted mental health outcomes during and post the pandemic. Mpondo et al. (2021) and Khumalo, Ejoke, Oppong Asante and Rugira (2021) provide excellent input on measures of psychological wellbeing, whilst van Wijk (2021) considers the usefulness of the stress overload scale for employed South Africans. Van Lil and Taylor (2021) provide recommendations for the more effective use of personality facets in predicting work related outcomes using the locally developed Basic Traits Inventory. 
Pienaar and Theron (2021) present research on the development and validation of a graduate leadership competency questionnaire arguing strongly for a measure that is able to assess a future generation of leaders thereby allowing for effective succession planning. AJOPA also publishes articles that discuss methodological developments in the field. In this volume, Pretorius (2021) argues for employing additional indicators beyond model fit indices to examine the factor structure of instruments of multidimensional instruments.

If one examines the download trends, it is clear that the journal is increasingly becoming recognised as the forum for assessment research in Africa attracting consistently more readers and submissions. This year, the journal was included in the Directory of Open Access Journals (DOAJ) and on the EBSCO database, and was accredited by the South African Department of Higher Education and Training. However, it is necessary for the journal to attract research from elsewhere in Africa beyond the southern region. Going forward, it is important that the journal considers strategies for the inclusion of more voices in the field. It is also vital for the journal to invite more contributions on the use of indigenous knowledge, beliefs and systems in psychological assessment.

In February 2020, academics from the University of Zambia presented a 2-day workshop at the University of the Witwatersrand, South Africa titled, 'Approaches to psychological assessment in Africa: Responsiveness to African cultural contexts in designing assessment methods'. The Panga Munthu Test, the Zambia cognitive assessment test, the Home Environment Potential Assessment schedule and the South African Personality Inventory were presented to stimulate discussions on projects for developing local and/or regional assessment measures that may be more suited to African contexts (Fetvadjiev, Meiring, Van de Vijver, \& Nel, 2018; Matafwali \& Serpell, 2014; Nabuzoka, 1993). The discussions held much promise for local and international projects wanting to focus on cross-cultural assessment. Of particular note was the interesting discussion on gamification in assessment and the use of indigenous games like Masikitlane - a local stone throwing game - as forms of assessment. Whilst there are many discussions and workshops of this nature across the African continent, much of this research remains unpublished. Hence, AJOPA provides a platform for the sharing of this research to find agile solutions for assessment across Africa. On behalf of the editors, editorial board and the publishers (AOSIS (Pty) Ltd and PsySSA), I would like to thank you for supporting this journal, to encourage you to submit your work to the journal, and to continue the conversation on psychological assessment across the continent.

\section{References}

Abdool Gafoor, L., Burke, A., \& Fourie, J. (2021). The efficacy of the senior South African Individual Scale Revised in distinguishing between attention deficit hyperactivity disorder, normal and sluggish cognitive tempo children. African Journal of Psychological Assessment, 3(0), a45. https://doi.org/10.4102/ajopa.v3i0.45

August, J., \& Mashegoane, S. (2021). Psychological assessment during and after the COVID-19 pandemic. African Journal of Psychological Assessment, 3(0), a74. https://doi.org/10.4102/ajopa.v3i0.74

Cockcroft, K. (2020). Ignorance is not an excuse - Irresponsible neurocognitive test use highlights the need for appropriate training. African Journal of Psychological Assessment, 2(0), a28. https://doi.org/10.4102/ajopa.v2i0.28

Dowdeswell, K., \& Kriek, H. (2021). Shifting assessment practices in the age of COVID-19. African Journal of Psychological Assessment, 3(0), a50. https://doi. org/10.4102/ajopa.v3i0.50

Fetvadjiev, V.H., Meiring, D., Van de Vijver, F.J.R., \& Nel, J.A. (2018). Indigenous personality structure and measurement in South Africa. In A.T. Church (Ed.), The Praeger Handbook of personality across cultures (pp. 137-160). Santa Barbara, CA: Preager.

Khumalo, I., Ejoke, U., Oppong Asante, K., \& Rugira, J. (2021). Measuring social wellbeing in Africa: An exploratory structural equation modelling study. African Journa of Psychological Assessment, 3(0), a37. https://doi.org/10.4102/ajopa.v3i0.37

Matafwali, B., \& Serpell, R. (2014). Design and validation of assessment tests for young children in Zambia. In R. Serpell \& K. Marfo (Eds.), Child development in young children in Zambia. In R. Serpell \& K. Marfo (Eds.), Child development in Africa: Views from inside. New Directions for Child and
2014(146), 77-96. https://doi.org/10.1002/cad.20074

Makhubela, M., \& Mashegoane, S. (2021). Psychometric properties of the Fear of COVID-19 Scale amongst black South African university students. African Journal of Psychological Assessment, 3(0), a57. https://doi.org/10.4102/ajopa.v3i0.57

Mpondo, F., Wray, C., Norris, S., Stein, A., Stein, A., \& Richter, L. (2021). Assessing psychological well-being measures amongst South African adults in the birth to twenty plus cohort. African Journal of Psychological Assessment, 3(0), a44. https://doi.org/10.4102/ajopa.v3i0.44

Munnik, E., Smith, M., Adams Tucker, L., \& Human, W. (2021). COVID-19 and psychological assessment teaching practices - Reflections from a South African university. African Journal of Psychological Assessment, 3(0), a40. https://doi. org/10.4102/ajopa.v3i0.40

Munnik, E., Wagener, E., \& Smith, M. (2021). Validation of the emotional socia screening tool for school readiness. African Journal of Psychological Assessment, 3(0), a42. https://doi.org/10.4102/ajopa.v3i0.42

Nabuzoka, D. (1993). How to define, involve and assess the care unit? Experiences and research from a CBR programme in Zambia. In $\mathrm{H}$. Finkenflügel (Ed.), The handicapped community. The relation between primary health care and community based rehabilitation (pp. 73-88). Amsterdam: VU University Press.

Pienaar, J., \& Theron, C. (2021). The development and validation of a graduate leader competency questionnaire: Arguing the need for a graduate leader performance measure. African Journal of Psychological Assessment, 3(0), a61. https://doi. org/10.4102/ajopa.v3i0.61

Pretorius, T. (2021). Over reliance on model fit indices in confirmatory factor analyses may lead to incorrect inferences about bifactor models: A cautionary note. African Journal of Psychological Assessment, 3(0), a35. https://doi.org/10.4102/ajopa. v3i0.35

Van Lill, X., \& Taylor, N. (2021). The manifestation of the 10 personality aspects amongst the facets of the Basic Traits Inventory. African Journal of Psychological Assessment, 3(0), a31. https://doi.org/10.4102/ajopa.v3i0.31

Van Wijk, C. (2021). Usefulness of the English version of the Stress Overload Scale in a sample of employed South Africans. African Journal of Psychological Assessment, 3(0), a41. https://doi.org/10.4102/ajopa.v3i0.41

Wigdorowitz, M., Rajab, P., Hassem, T., \& Titi, N. (2021). The impact of COVID-19 on psychometric assessment across industry and academia in South Africa. African Journal of Psychological Assessment, 3(0), a38. https://doi.org/10.4102/ajopa.v3i0.38 